\title{
Ensino de Química na Educação Básica: Construindo Conhecimentos a Partir da Produção de Sabão
}

\author{
Teaching Chemistry in Basic Education: Building Knowledge From the \\ Production of Soap
}

\section{Enseñanza de la Química en la Educación Básica: Construcción de Conocimientos a Partir de la Producción de Jabón}

\author{
Jacqueline Pereira Gomes, (jacquelinesolnet@gmail.com) \\ Universidade Estadual da Paraíba-UEPB. \\ Francisco Ferreira Dantas Filho, (dantasquimica@yahoo.com.br) \\ Universidade Estadual da Paraíba-UEPB.
}

Resumo: Esta pesquisa é parte do trabalho de dissertação de Mestrado do Programa de Pós Graduação em Ensino de Ciências e Educação Matemática - PPGECEM/UEPB em parceria com o Grupo de Pesquisa em Metodologias para a Educação Química GPMEQ. A mesma teve como objetivo, construir conhecimentos científicos através da composição Química do sabão, proporcionando aos estudantes da $3^{\text {a }}$ Série do Ensino Médio (EM), uma melhor compreensão sobre as reações de saponificação. Trata-se de uma pesquisa exploratória, com abordagem qualitativa. Este trabalho foi realizado no ano de 2020, com 63 estudantes pertencentes a duas turmas da $3^{\text {a }}$ Série do EM, de uma Escola Estadual do município de Soledade-PB. O instrumento de coleta de dados, partiu da observação dos pesquisadores durante o desenvolvimento do experimento. Através do instrumento de coleta de dados, foi possível compreender, o quanto a inserção de temas geradores nas metodologias de ensino de Química, contribuem no processo de ensino e aprendizagem do educando.

Palavras-chave: Educação Básica; Reações de Saponificação; Sabão.

Abstract: This research is part of the Master's thesis work of the Postgraduate Program in Teaching of Science and Mathematical Education - PPGECEM / UEPB in partnership with the Research Group on Methodologies for Chemical Education GPMEQ. It aimed to build scientific knowledge through the chemical composition of soap, providing students in the 3rd Grade of High School (EM) with a better understanding of saponification reactions. This is an exploratory research, with a qualitative approach. This work was carried out in the year 2020, with 63 students belonging to two classes of the 3rd Grade of EM, from a State School in the municipality of Soledade-PB. The data collection instrument was based on the observation of the researchers during the development of the experiment. Through the data collection instrument, it was possible to understand how much the insertion of 
generating themes in the teaching methodologies of Chemistry, contribute to the process of teaching and learning the student.

Keywords: Basic Education; Saponification Reactions; Soap.

Resume: Esta investigación forma parte del trabajo de tesis de maestría del Programa de Postgrado en Docencia de las Ciencias y Educación Matemática - PPGECEM / UEPB en alianza con el Grupo de Investigación en Metodologías para la Educación Química - GPMEQ. Tenía como objetivo construir conocimiento científico a través de la composición química del jabón, proporcionando a los estudiantes de 3er Grado de Bachillerato (EM) una mejor comprensión de las reacciones orgánicas de la saponificación. Es una investigación exploratoria, con enfoque cualitativo. Este trabajo se realizó en el año 2020, con 63 alumnos pertenecientes a las clases del 3er Grado de EM, de un colegio público del municipio de Soledade-PB. Los estudiantes tenían entre 16 y 22 años. La herramienta de recolección de datos se inició con la aplicación de actividades de investigación sobre el tema del jabón y también de un taller para producir jabón. A través del instrumento de recolección de datos, puedo comprender en qué medida la inserción de temas generativos en los métodos de enseñanza de la química, contribuye al proceso de aprendizaje y aprendizaje del aluminio.

Palabras-Chave: Educación Básica; Reacciones de saponificación orgánica; Jabón.

\section{INTRODUÇÃO}

O uso de temas geradores no ensino de Química se tornou uma ferramenta essencial para o processo de ensino-aprendizagem por ser a Química uma ciência experimental. Sabe-se que a disciplina de Química Orgânica, vem trazendo contribuições importantes para o ensino e aprendizagem dos discentes na escola. A Química Orgânica se apoia no tripé: nomenclatura, estrutura e propriedades (BOTH, 2007).

Devido ao fato da Química Orgânica exibir uma variedade gigantesca de compostos, estudá-la, necessita de grandes subjetividades e inteligência espacial (NETO; LIMA, 2010). Para Goodwin (2010) o estudo da Química Orgânica, possibilita um território abundante para o exercício e domínio do papel das representações ilustrativas na explicação científica.

Marcondes et al. (2015) consideram também que a Química Orgânica:

Trata da classificação dos tipos de cadeias, classificação dos tipos de carbonos, classificação dos tipos de ligações, classificação dos tipos de hidrocarbonetos, classificação dos tipos de isomeria, regras para dar nomes 
aos compostos, regras para escrever as fórmulas moleculares, estruturais e de traços de compostos orgânicos etc. [...] Muitas vezes os estudantes passam um ano inteiro treinando a aplicação de inúmeras regras para classificar, nomear e formular compostos orgânicos com pouquíssimos momentos de reflexão sobre conteúdos de fato relevantes para a cidadania ou para o desenvolvimento da capacidade de interpretar o mundo físico presente em seu cotidiano e na mídia. (MARCONDES et al., 2015, p.11).

O estudo de Química Orgânica na educação básica, precisa fornecer condições para que os educandos sejam capazes de compreender de forma aperfeiçoada, a vida de parte dos materiais que os cercam cotidianamente (VALENTIM, 2017).

Segundo Freire (2011) é preciso utilizar os temas geradores como ferramentas que proporcionem aprendizagem do educando, resultando assim, em uma mediação entre as responsabilidades dos docentes e os interesses dos estudantes. Alves e Toutonge (2020) valorizam a aprendizagem cotidiana e estabelecem relações entre o ensino de ciência e o tema gerador, água.

De acordo com Freire (1970) o olhar de criticidade na perspectiva CTSA está relacionado ao ensino problematizador, com características reflexivas, de proteção a autenticidade, em que a educação tem por finalidade promover o diálogo entre o professor e o educando, em um cenário de exercício para a liberdade.

Aliar a teoria à prática é fundamental principalmente quando se trata de uma disciplina como esta. Pensar em metodologias que valorizem e que resgatem esses conhecimentos é essencial para ensinar atualmente.

É importante que o educador realize a interação do discente com a disciplina de Química. Quando o docente alcança a comunicação com o estudante aproximando o conhecimento e o conteúdo, é possível que o estudante compreenda de forma significativa a disciplina de Química (RIBEIRO; BARRETO, 2012).

Para Freire (2003) aprender a escutar o discente é respeitar e estimar a sua vida, sua educação de mundo que traz consigo. A função respeitável do docente, é fazer com que o estudante possua autonomia e caminhe em benefício da liberdade (FREIRE, 1996). 
Para levar o aluno ao conhecimento, é fundamental que o professor provoque o estímulo, o pensamento crítico e o prazer de manifestá-lo para que, assim, ocorra um constante equilíbrio no aprendizado do estudante.

Utilizar o tema gerador, sabão, para ensinar Química, vem somar ao ensino de Química Orgânica, pois, de forma alternativa pode-se ensinar respectivos conteúdos valorizando os contextos científicos e sociais e cuidando do meio ambiente. Sabe-se que o sabão não é produzido pela natureza, mas que pode ser obtido através de um procedimento simples.

O sabão é utilizado desde a antiguidade. Sua origem se deu, através da fervura de gordura animal que estava contaminada com cinzas. Um conto Romano fala que o sabão se originou da mistura entre, cinza vegetal e sebo animal (REIS, 2009).

Os egípcios banhavam papiros regularmente, com uma mistura de óleos animais e vegetais que possuíam características parecidas com a do sabão (NETO; DEL PINO, 2009). Nessa época não existiam técnicas para fabricar sabão, utilizava-se apenas o método de tentativa e erro (BALDASSO et al., 2010).

No Brasil, o sabão passou a ser utilizado somente depois da segunda metade do século XXI. Mercadante (2009) explica que as qualidades de sabões fabricados, variam de acordo com os ingredientes que são utilizados.

A molécula constituinte do sabão faz parte da função orgânica sal, sendo assim, a mesma, possui no mínimo uma ligação com característica tipicamente iônica, tornando assim, polar. A polaridade, assim como, o tamanho da cadeia, faz com que o sabão se dissolva em substâncias polares e apolares, e até mesmo em ambas simultaneamente. É essa característica, que possibilita ao sabão a ação de limpeza (DEL PINO; NETO, 2009). O sabão apresenta ação detergente, que ajuda na limpeza (BARBOSA; SILVA, 1995).

Neto e Del Pino (2009) explicam que o sabão é produzido através, de uma reação Química entre um ácido graxo (gorduras e óleos vegetais ou animais) com um material de caráter básico. Normalmente, a base usada é o hidróxido de sódio $(\mathrm{NaOH})$, conhecido popularmente como soda cáustica. Quando a gordura é aquecida na presença 
do hidróxido de sódio, acontece uma reação química denominada saponificação (PERUZO; CANTO, 2010).

Peruzzo e Canto (2010) explicam que a reação de saponificação além de produzir sabão, também produz glicerol, que é um composto orgânico pertencente ao grupo dos álcoois.

A potencialidade de limpeza dos sabões, depende da sua habilidade de formar emulsões com elementos solúveis nas gorduras. Na emulsão, as moléculas de sabão embrulham a "sujeira" de modo a colocá-la em um envelope solúvel em água, denominada micela (FERREIRA; MUNCHEN, 2012).

Muitas pessoas produzem sabão em casa e a fabricação do mesmo sustenta algumas famílias, além de evitar impactos ambientais. Segundo Alberici e Pontes (2004) a fabricação de sabão caseiro minimiza a quantidade de óleo de fritura, que são descartados de forma irregular no meio ambiente.

Devido ao sabão ser um produto que está presente na vida dos alunos, e devido a sua fabricação envolver processos químicos simples, ele pode ser inserido nas metodologias de ensino de Química (OLIVEIRA, 2006).

Nesse contexto, podemos constatar que a utilização do tema gerador, produção de sabão a partir da reutilização do óleo de fritura, possibilita o pensamento reflexivo dos alunos para compreender o mundo que o cerca. Diante do exposto, esta pesquisa objetiva construir conhecimentos científicos através da utilização de metodologias alternativas e inovadoras partido da temática sabão, de forma que proporcione aos estudantes da $3^{\text {a }}$ Série do EM, uma compreensão melhor sobre as reações de saponificação.

\section{METODOLOGIA}

Esta pesquisa caracteriza-se como exploratória, estando em acordo com Gil que afirma que, "as pesquisas exploratórias proporcionam maior familiaridade com o problema, com vistas a torná-lo mais explícito ou a construir hipóteses” (GIL, 2010, p.27). A pesquisa também apresenta abordagem qualitativa, pois, de acordo com Gatti e André (2011) a pesquisa qualitativa, viabiliza, a melhor compreensão dos processos 
escolares de relações e aprendizagem, processos institucionais e culturais, de socialização e sociabilidade, o cotidiano escolar em suas múltiplas implicações.

A pesquisa foi realizada no ano de 2020, o público alvo foram 63 estudantes pertencentes a duas turmas da $3^{\text {a }}$ Série do EM, de uma escola estadual do município de Soledade-PB. Os estudantes estavam com idade entre 16 e 22 anos. O instrumento de coleta de dados, partiu da observação dos pesquisadores durante o desenvolvimento do experimento.

Inicialmente, os discentes foram convidados a realizarem uma pesquisa sobre a reutilização de óleos de fritura para fabricação de sabão, e sua importância no cotidiano. Em seguida, deu-se a oportunidade aos estudantes para expor os resultados da pesquisa. O Quadro 1 apresenta algumas questões que foram solicitadas aos discentes, e para responderem às questões eles utilizaram os seus cadernos.

Quadro 1 - Atividade aplicada aos alunos da $3^{\text {a }}$ Série do Ensino Médio

\section{Atividade do aluno}

1- Pesquise: O que é sabão? Como são formados? Qual é a matéria prima utilizada na produção do sabão?

2- Pesquise e responda: Qual é a diferença entre óleo e gordura?

3- Apresentação da sua pesquisa para os colegas e o professor.

Fonte: Dados do autor, 2020.

A atividade foi aplicada aos estudantes da $3^{\text {a }}$ série do EM, como eles já haviam estudado os conceitos de funções orgânicas, eles detinham de conhecimentos sobre as questões aplicadas.

Sequencialmente, deu-se início a explicação sobre a funcionalidade do sabão, características e potencial de limpeza, para isso, os estudantes precisaram responder alguns questionamentos acerca da estrutura do sabão, a ação de limpeza dos sabões, sobre emulsão e sobre, se o sabão poderia falhar na sua ação de limpeza.

Para a investigação destas questões, utilizou-se também dos pressupostos teóricos da análise de conteúdo de Bardin (2011) que fala que: “A análise do conteúdo é 
um conjunto de instrumentos de cunho metodológico em constante aperfeiçoamento, que se aplicam a discursos (conteúdos e continentes) extremamente diversificados".

Por fim, realizou-se uma oficina para fabricar sabão a partir do óleo já utilizado em frituras. No Quadro 2 estão apresentados os materiais e os reagentes que foram utilizados para produzir o sabão a partir do óleo residual de cozinha.

Quadro 2 - Materiais e reagentes utilizados na produção do sabão

\begin{tabular}{|l|l|}
\hline \multicolumn{1}{|c|}{ Reagentes } & \multicolumn{1}{c|}{ Materiais } \\
\hline $1000 \mathrm{~mL}$ de óleo de fritura usado. & Luvas descartáveis. \\
\hline $170 \mathrm{~mL}$ de água. & Máscara descartável. \\
\hline $73 \mathrm{~g}$ de hidróxido de sódio $(\mathrm{NaOH})$. & Balança. \\
\hline 1 limão (coado). & Balde. \\
\hline Essência. & Colher de madeira. \\
\hline $25 \mathrm{~mL}$ de álcool etílico. & Potes plásticos. \\
\hline
\end{tabular}

Fonte: Dados do autor, 2020.

\section{$\checkmark$ Procedimento Experimental}

Antes de iniciar a prática, os alunos, foram orientados a colocarem máscaras e luvas, pois, o hidróxido de sódio $(\mathrm{NaOH})$ é uma substância corrosiva, portanto, deveria ser manuseado com cuidado.

Inicialmente, os alunos realizaram a pesagem de 73 gramas de hidróxido de sódio $(\mathrm{NaOH})$, após a pesagem, colocou o hidróxido de sódio em um balde, acrescentou um pouco de água, mexeu até dissolver. Em seguida, homogeneizou e reservou. A Figura 1 apresenta a realização da pesagem do hidróxido de sódio.
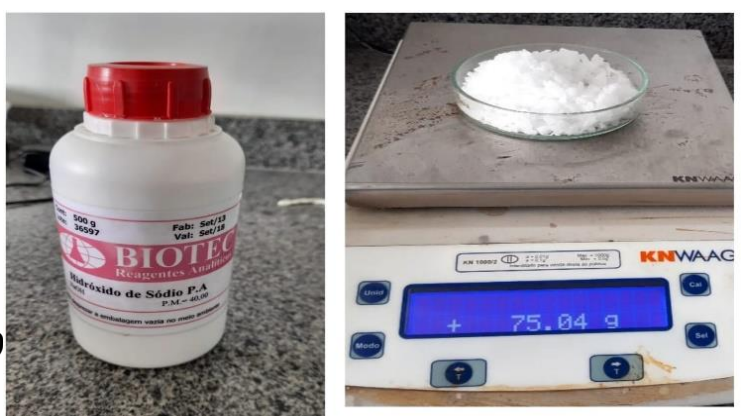
Figura 1- Pesagem do hidróxido de sódio

Fonte: Dados do autor, 2020.

Posteriormente, em um béquer de $1000 \mathrm{~mL}$, foi medido o volume de óleo, oriundo de fritura. Em seguida, adicionou-se na solução presente no balde, sob agitação por cerca de 20 minutos. Na sequência, foi adicionado $100 \mathrm{~mL}$ de água, o suco do limão e a essência, e mexeu por 5 minutos. Posteriormente, colocou-se $25 \mathrm{~mL}$ de álcool etílico, e mexeu por mais 10 minutos. Após concluir a saponificação, o sabão, foi acondicionado em potinhos plásticos.

\section{RESULTADOS E DISCUSSÕES}

Antes de iniciar o experimento, os pesquisadores, revisou o conceito de sabão, lembrando que estes são sais de ácidos graxos obtidos pela reação entre um glicerídeo e uma base forte, essa reação é chamada de reação de saponificação.

Os sabões obtidos com $\mathrm{NaOH}$ (sabões de sódio) possuem consistência mais dura e normalmente são usados na fabricação de sabões em barra. Já os sabões obtidos na reação com KOH (sabões de potássio) possuem consistência mais flácida e, em geral, são usados na fabricação de sabonetes líquidos e cremes de barbear.

\subsection{FABRICAÇÃO DE SABÃO A PARTIR DO ÓLEO UTILIZAdOS EM FRITURAS}

Esse experimento foi realizado de forma alternativa com materiais de baixo custo. O mesmo teve a intenção de alertar os sujeitos envolvidos, sobre os impactos ambientais gerados, devido ao descarte inadequado de óleo de fritura no meio ambiente, e principalmente nas redes de esgotos. De acordo com Bortoluzzi (2011) quando os óleos são liberados na rede de esgoto, eles são acumulados e ficam retidos nas encanações, de modo à, dificultar a passagem de água e gerar entupimentos e mau funcionamento das redes de esgoto. 
Essa prática trabalhou com o experimento do sabão, em uma perspectiva CTSA, buscando assim, valorizar os saberes populares, ampliando assim, a visão dos sujeitos sobre a utilização da ciência e da tecnologia na sociedade. Ensinar na perspectiva CTSA, faz com que os conteúdos sejam contextualizados, por aproximações sociais, que incentivem a tomada de decisão, assim como, a inevitabilidade de envolver a ciência e a sua função no meio social (SANTOS, 2007).

Com a realização do experimento, os discentes aprenderam a fazer sabão e também a cuidar do meio ambiente, através da reutilização de óleos provenientes de fritura. A Figura 2 apresenta o sabão feito pelos discentes durante a realização da oficina.
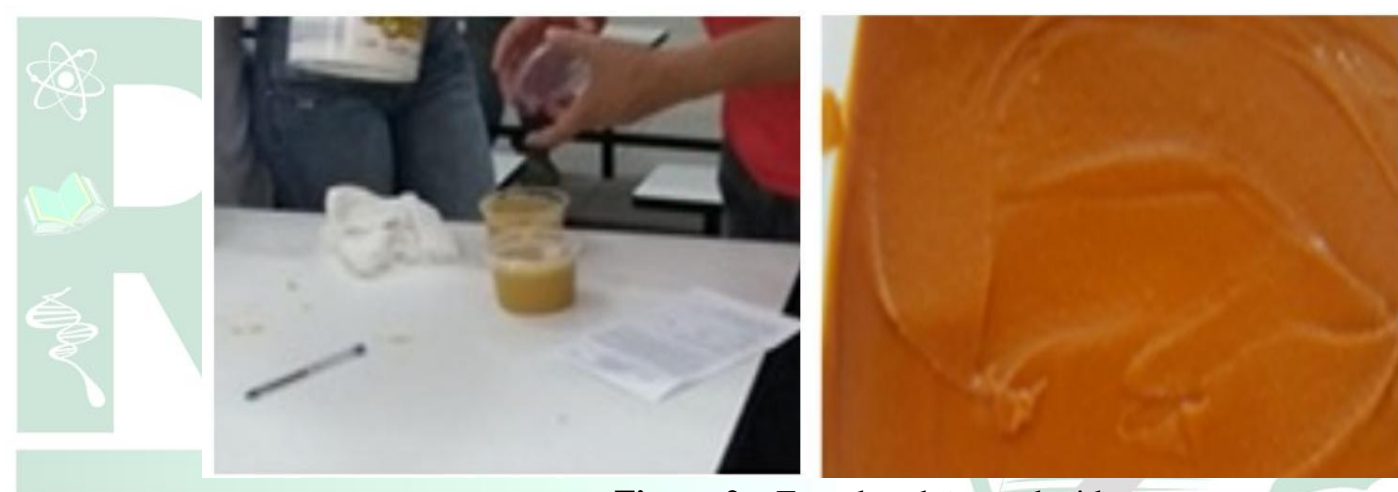

Figura 2 - Foto do sabão produzido

Fonte-Dados do autor, 2020.

A Figura 2 apresenta o sabão produzido. Como o hidróxido de sódio ainda estava bastante ativo foi necessário que o sabão fosse guardado por 30 dias, tempo necessário para a sua cura. Após esse período o sabão estava pronto para uso. Posteriormente, mediu-se o $\mathrm{pH}$ do mesmo, com o auxílio de uma fita de $\mathrm{pH}$. Após análises do $\mathrm{pH}$, observou-se que o sabão apresentou um $\mathrm{pH} 10$. Corroborando com Ozago (2008), segundo o pesquisador o pH do sabão é aproximadamente 10.

Com a prática, os alunos puderam aprender alguns dos procedimentos tecnológicos que são utilizados em uma indústria de fabricação sabão e os cuidados que se deve tomar ao descartar resíduos diretamente no meio ambiente sem realizar o tratamento adequado para poder minimizar esses impactos ambientais causados por reagentes químicos e pelo homem. 


\subsection{DIRECIONAMENTO DAS ATIVIDADES}

Os discentes foram convidados a responderem o questinamento presente no Quadro 1 que encontrasse exposto na metodologia. A Figura 3 mostra uma das respostas atribuídas por um dos estudantes em seu caderno.

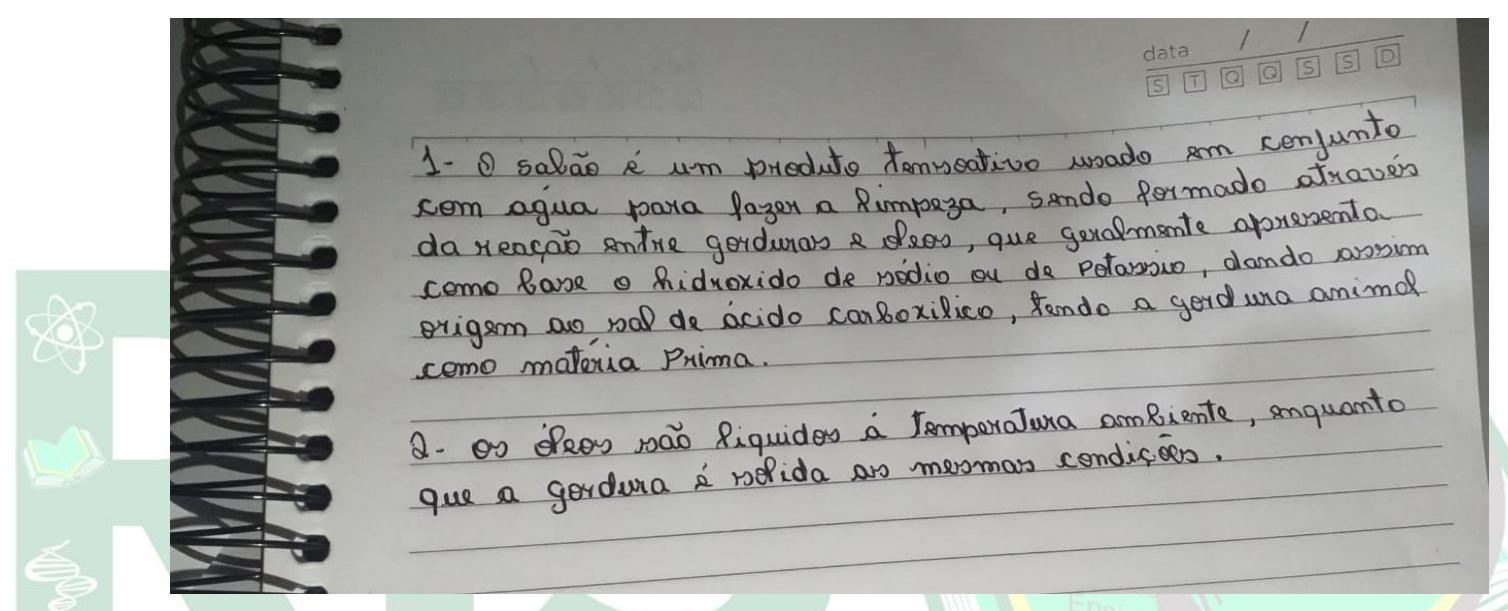

Figura 3- Foto do caderno do aluno

Fonte - Dados do autor, 2020.

A Figura 3 apresenta um registro feito, em um caderno pertencente a um dos discentes participantes da pesquisa. Ao expor suas respostas foi possível observar que os estudantes possuíam um certo conhecimento sobre o sabão, e apresentaram respostas coerentes a pesquisa solicitada. O sabão é um produto utilizado na lavagem e limpeza doméstica, formado à base de sais alcalinos e de ácidos graxos associados ou não a outros tensoativos (ANVISA, 2015).

Ainda sobre a primeira questão da pesquisa, completa-se que, entre as gorduras de origem animal a mais usada para fabricação de sabão é a gordura bovina. Entre as gorduras vegetais, as mais usadas para essa finalidade são: o óleo de dendê e o óleo de coco (NEVES, 2003).
} 
Completa-se a primeira questão, com a explicação de que, o sabão é uma mistura de várias substâncias químicas, unidas por duas matérias-primas: os triacilglicerídeos e o hidróxido (CAOBIANCO, 2015).

Para a segunda questão, trouxe as considerações de (Castro 2014, p.3) que explica que a diferença entre óleo e gordura é que "nos óleos predominam glicerídeos de ácidos insaturados e são líquidos na temperatura ambiente, já nas gorduras predominam glicerídeos de ácidos saturados, e são sólidas em temperatura ambiente”.

\subsection{CONSTRUÇÃO DOS CONHECIMENTOS CIENTÍFICOS A PARTIR DA TEMÁTICA SABÃO}

Esse momento marcou-se pela realização de discussões acerca da estrutura e ação de limpeza do sabão, para isso, os pesquisadores fizeram uma pequena demonstração de uma micela utilizando palitos de fósforo e isopor, para explicar como as moléculas de sabão se envolvem na "sujeira" de modo a eliminá-las. A Figura 4 expõe a representação de uma micela.

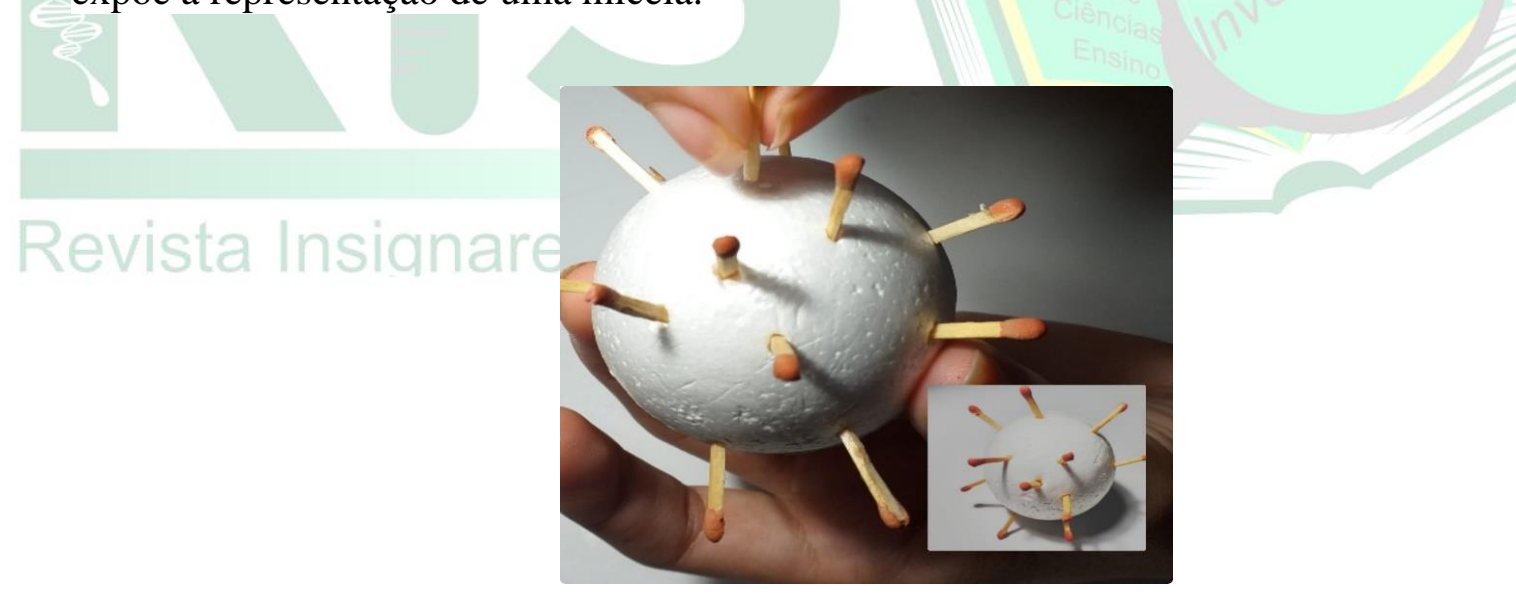

Figura 4 - Representação da micela

Fonte - Dados do autor, 2020.

A Figura 4 apresenta a representação de uma micela, utilizando palito de fósforo e uma bolinha de isopor. Os palitos de fósforos representam o sabão, em que as pontinhas vermelhas dos palitos simbolizam a parte polar do sabão, e as partes compridas dos palitos representam a parte apolar da molécula do sabão, elas se encontram presa na bolinha de isopor a qual representa a molécula de gordura, que 
também é apolar, e como, semelhante dissolve semelhante, a parte apolar do sabão reage com a parte apolar da molécula de gordura e assim, realiza-se o processo de remoção da "sujeira".

As interações da água com a sujeira e com o sabão resultam numa formação de estruturas capazes de interagir com a sujeira e se dissolver em água, as quais são chamadas de micelas. A formação das micelas permite com que a sujeira seja eliminada com a água durante o processo de limpeza (NETO; DEL PINO, 2009). Por isso, a habilidade de limpeza dos sabões ou detergentes não está ligado ao seu poder de formar espuma, mas sim, de sua capacidade de formar micelas estáveis, que puxam com agilidade as moléculas de gorduras introduzidas no objeto que irá ser limpo.

Sequencialmente, os pesquisadores sugeriram aos estudantes que montassem sua própria micela e para isso eles poderiam utilizar sua criatividade para confeccionar a mesma. A Figura 5 mostra algumas das micelas criadas pelos estudantes.

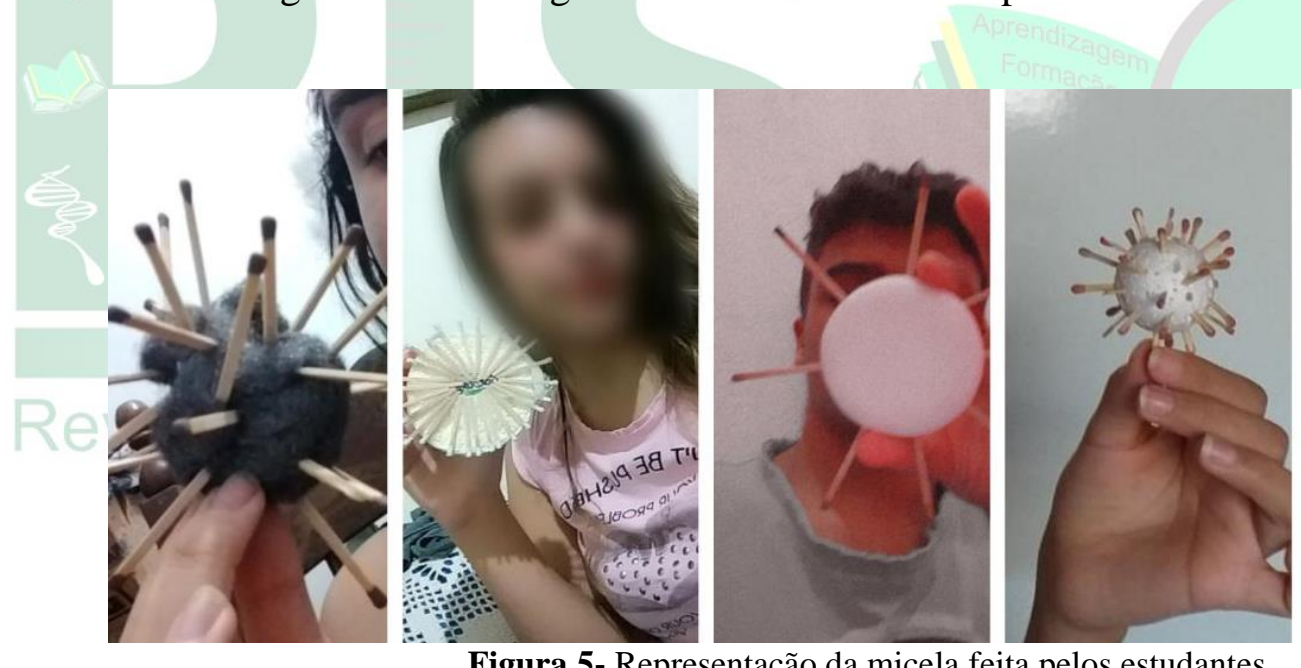

Figura 5- Representação da micela feita pelos estudantes

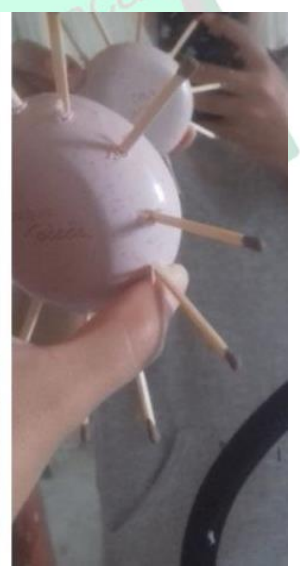

Fonte - Dados do autor, 2020.

Na Figura 5 encontra-se exposto imagens da construção de algumas micelas pelos alunos da $3^{\text {a }}$ série do EM, para isso, contou-se com a criatividade de cada estudante, e eles poderiam fazer a representação com auxílio de vários outros materiais. Alguns fizeram a representação da gordura com esponja de aço, outros com bolinha de isopor, ou com massinha de modelar. Para o sabão alguns utilizaram palitos de fósforo, outros alfinetes e assim por diante. Com essa atividade, foi possível observar que os 
estudantes compreenderam de certa forma o que era uma micela, e como a mesma atuava durante a ação de limpeza.

Diante dessa observação, questionou-se os 63 estudantes sobre, como acontece a formação de micelas. As respostas fornecidas pelos estudantes encontram-se expostas no Quadro 3.

Quadro 3 - Atuação do sabão na remoção de gorduras

\begin{tabular}{|c|c|c|}
\hline \multicolumn{3}{|c|}{$\begin{array}{c}\text { CATEGORIA: } \\
\text { COMO ACONTECE A FORMAÇÃO DAS MICELAS? JUSTIFIQUE. }\end{array}$} \\
\hline SUBCATEGORIAS & $\mathrm{N}^{0}$ DE FALAS & RESPOSTAS \\
\hline $\begin{array}{l}\text { Os estudantes que acreditam que a } \\
\text { micela criam uma estrutura que } \\
\text { envolve o sabão. }\end{array}$ & 29 & $\begin{array}{l}\text { "O Bombril está representando as moléculas } \\
\text { de gordura e os palitos representam as micelas } \\
\text { (Moléculas de sabão) As micelas criam uma } \\
\text { estrutura envolvendo a sujeira. (Aluno 22) }\end{array}$ \\
\hline $\begin{array}{l}\text { Os discentes compreendem que a } \\
\text { micela é formada por uma parte } \\
\text { polar e outra apolar. }\end{array}$ & & $\begin{array}{l}\text { "No experimento usei palha de aço para } \\
\text { representar a sujeira e o palito de fósforo as } \\
\text { micelas, o cabo do palito representando a parte } \\
\text { apolar e a parte da "cabeça" a Polar", que } \\
\text { interagem com a água". (Aluno 2) }\end{array}$ \\
\hline $\begin{array}{l}\text { Os alunos acreditavam que a } \\
\text { micela era formada por partes que } \\
\text { tinham semelhanças entre si. }\end{array}$ & 2 & $\begin{array}{l}\text { "O sabão possui tanto moléculas polares como } \\
\text { apolares. A parte apolar do sabão interage } \\
\text { com a gordura, enquanto a parte polar } \\
\text { interage com a água (polar) ou seja, } \\
\text { semelhante dissolve semelhante, assim o sabão } \\
\text { torna solúvel gotículas de gorduras na água } \\
\text { removendo a sujeira, formando assim as } \\
\text { micelas". (Aluno 5) }\end{array}$ \\
\hline $\begin{array}{l}\text { Os discentes acreditam que o } \\
\text { sabão conseguia limpar devido a } \\
\text { sua estrutura Química. }\end{array}$ & 4 & $\begin{array}{l}\text { "A micela era como o sabão consegue limpar, } \\
\text { através da sua fórmula Química e como elas } \\
\text { agem para que tudo isso aconteça". (Aluno } \\
\text { 32) }\end{array}$ \\
\hline
\end{tabular}

Fonte - Dados do autor, 2020.

No Quadro 3 pode-se observar que 29 discentes, falaram que as micelas tratavam-se de uma estrutura que envolvia o sabão, 21 estudantes compreendiam que as micelas eram formadas por uma parte polar e outra apolar, 9 alunos acreditavam que as micelas possuíam semelhanças entre si, 4 estudantes responderam que o sabão possuí a capacidade de limpeza devido a sua estrutura Química. De acordo com Ferreira e Munchen (2012) a organização das micelas, proporcionam a eliminação de gordura, devido às moléculas de gorduras ficarem presas nas extremidades hidrofóbicas de sabões. 


\subsubsection{Entendendo a funcionalidade do sabão}

Com o objetivo de facilitar a aprendizagem dos estudantes, como também sanar todas as dúvidas relacionadas a atuação dos sabões, os alunos, foram convidados a responder as seguintes indagações: I - Escreva a estrutura do sabão; II- Defina água dura e água pesada; III- Qual a diferença entre sabão e detergente?

Para a realização da atividade, os pesquisadores dividiram a sala em grupos, compostos por quatro estudantes, e eles iriam responder à pesquisa no seu caderno. A seguir, serão expostas às respostas fornecidas pelos alunos.

Inicialmente os discentes foram convidados a escrevessem a estrutura Química do sabão. A Figura 6, apresenta uma das respostas atribuídas pelos estudantes pesquisados.

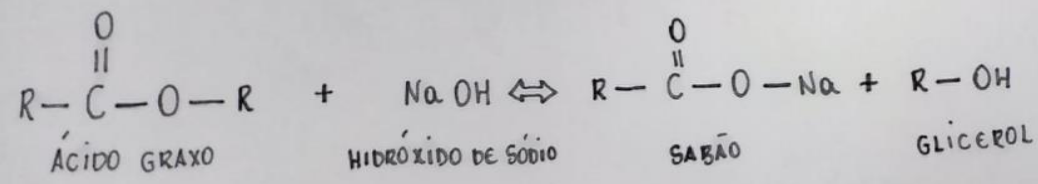

Figura 6- Escreva a estrutura do sabão

Fonte - Dados do autor, 2020.

Na Figura 6 está exposta à reação Química para a obtenção do sabão, pode-se observar que o mesmo é obtido, através de uma reação entre um ácido graxo (Estér) com o hidróxido de sódio, em que a reação resulta na produção de sabão e glicerol. De acordo com, Verani (2001) a reação Química do sabão também pode ser chamada de hidrólise alcalina, e a mesma acontece quando um éster em solução aquosa de base inorgânica produz um sal orgânico e álcool.

Posteriormente, foi solicitado aos estudantes que eles definissem água dura e água pesada. De modo a instigar o aluno em relação a esse questionamento, a professorapesquisadora disponibilizou aos participantes, dois recipientes. $\mathrm{O}$ primeiro, continha água de origem de um poço artesiano (água dura). O segundo, continha água da cisterna 
que havia sido captada da chuva. A Figura 7 apresenta a água dura e a água da cisterna após serem adicionadas algumas gotas de detergente a elas.
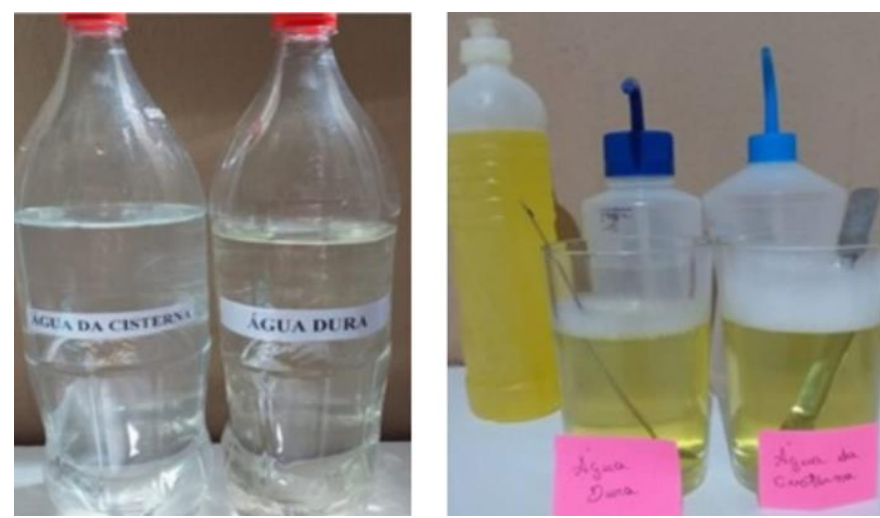

Figura 7- Água dura e água da cisterna Fonte - Dados do autor, 2020.

A Figura 7 apresenta a água dura e a água da cisterna que foram utilizadas. $\mathrm{Na}$ imagem a esquerda observam-se duas garrafas Pet, a primeira garrafa possuí água da cisterna, enquanto, a segunda garrafa apresenta água dura (poço). A imagem à direita, apresenta dois copos, no copo à esquerda apresentava-se água dura e no copo à direita água da cisterna, ambos continham algumas gotas de detergente e foram agitados com o auxílio de uma espátula.

A potencialidade tensoativa do sabão se reduz na presença de águas duras, que se caracterizam como águas que contêm muitos cátions, como o cálcio $\left(\mathrm{Ca}^{2+}\right), \mathrm{o}$ magnésio $\left(\mathrm{Mg}^{2+}\right)$ e o ferro $\left(\mathrm{Fe}^{2+}\right)$, ou até mesmo a água salgada, o que inibe o seu papel de limpeza. Isso ocorre, devido à interação desses sais com a molécula de sabão, por uma reação de substituição, formam-se sais insolúveis, sendo possível observar a formação de um precipitado. E nessa situação, não acontece formação de espuma, nem limpeza, devido à redução da atuação emulsificante da sujeira (NETO; DELPINO, 2009).

Após a demonstração do experimento, e com o objetivo de resgatar os conceitos químicos, sobre os vários tipos de água os estudantes foram convidados a responder ao seguinte questionamento: na sua opinião qual a diferença entre uma água dura água dura 
e uma água pesada. As respostas atribuídas pelos discentes, encontram-se expostas no

Quadro 4.

Quadro 4 - Definição de água dura e água pesada

\begin{tabular}{|c|c|c|}
\hline \multicolumn{3}{|c|}{$\begin{array}{l}\text { CATEGORIA: } \\
\text { GUA DURA E ÁGUA PESADA? }\end{array}$} \\
\hline SUBCATEGORIAS & $\mathbf{N}^{\circ}$ DE FALAS & RESPOSTAS \\
\hline $\begin{array}{l}\text { Os estudantes explicaram que a } \\
\text { diferença estava nas propriedades da } \\
\text { água e que a água dura é utilizada na } \\
\text { fissão nuclear. }\end{array}$ & 60 & $\begin{array}{l}\text { "Água dura é formada pelo hidrogênio } \\
\text { deutério, podendo ser chamada também } \\
\text { de Água Deuterada. Já a Água dura é } \\
\text { rica em sais minerais e cátions } \\
\text { metálicos e é muito utilizada para } \\
\text { diminuir a ação de limpeza do sabão, já } \\
\text { a Água pesada é utilizada no controle } \\
\text { da velocidade dos neutros e no processo } \\
\text { de fissão nuclear". (Aluno 3) }\end{array}$ \\
\hline $\begin{array}{l}\text { Os discentes acreditam que a água dura } \\
\text { não formava espuma enquanto a água } \\
\text { dura continha deutério em sua } \\
\text { composição }\end{array}$ & 3 & $\begin{array}{l}\text { "Água pesada: é o óxido de deutério. } \\
\text { Água dura: não forma espuma com } \\
\text { sabão". (Aluno 55) }\end{array}$ \\
\hline
\end{tabular}

Fonte - Dados do autor, 2020.

No Quadro 4, encontra-se expostas às respostas atribuídas pelos discentes ao questionamento, observa-se que 60 discentes, explicaram que a diferença de água dura e água pesada, estava nas propriedades da água e que a água dura é utilizada na fissão nuclear. Sequencialmente, 3 discentes, acreditavam que água dura não formava espuma, e a água pesada continha deutério em sua composição.

De acordo com Silva e Carvalho (2007) as águas duras são águas provenientes de poços e que precisam ser tratadas para que produzam mais espumas, e o tratamento acontece através de abrandamento por precipitação Química ou por troca iônica, este último possui eficiência, porém, apresenta alto custo. Já água pesada ou deuterada, possuem propriedades físico-químicas, diferentes devido à diferença de massa atômica do deutério e do hidrogênio (KATZ, 1960).

Por fim, os discentes foram questionados sobre, qual seria a diferença entre o sabão e o detergente. A Figura 8 apresenta a resposta de um dos alunos pesquisados. 


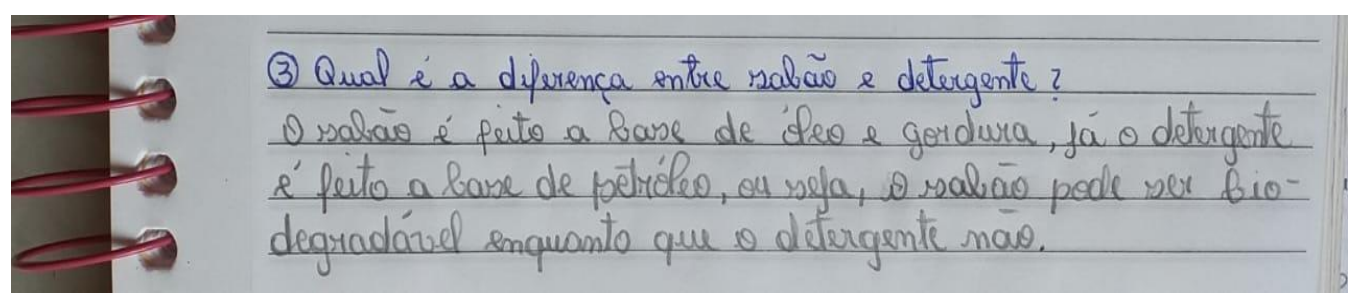

Figura 8- Qual a diferença entre sabão e detergente

Fonte - Dados do autor, 2020.

A Figura 8 apresenta um registro feito do caderno do aluno referente a pesquisa solicitada. A resposta apresentada pelo estudante é coerente, visto que, os sabões e os detergentes diferem entre si, devido processo de fabricação e de obtenção, assim como, a composição Química de cada um, fazem com que eles atuem de forma diferente (CASTRO, 2009). Visto que, o sabão é composto por sais de sódio e de potássio de inúmeros ácidos graxos. Enquanto, os detergentes são misturas complexas de diferentes componentes para que sejam capazes de efetuar uma ação própria durante a limpeza (CASTRO, 2009).

\section{CONSIDERAÇÕES FINAIS}

A concretização do presente estudo foi de suma importância para o processo de ensino e aprendizagem dos discentes. A utilização da temática produção de sabão, contribuiu na compreensão dos conceitos de Química abordados. Nesse aspecto, foi observado que o uso da temática produção sabão utilizando óleo de fritura, pode ser uma estratégia didática para potencializar as aulas de Química no Ensino Médio, possibilitando ao aluno refletir sobre a importância e aplicação dos conceitos químicos no cotidiano.

Este trabalho, despertou o senso crítico e criativo dos estudantes participantes da pesquisa. O objetivo da pesquisa foi alcançado de forma satisfatória. De acordo com os resultados obtidos, é possível observar que os estudantes conseguiram compreender como acontece a reação de saponificação, assim como, entender as propriedades físicoquímicas do sabão. 
Os resultados da pesquisa mostram que o índice de aceitação da temática aplicada foi significativo. Destarte, que o uso de temas geradores, como a produção de sabão, nas aulas de Química, vislumbra despertar curiosidade, motivação e interesse nos alunos para estudo da Química.

Diante dos resultados colhidos nesta pesquisa, foi possível constatar que ensinar Química por meio de temas geradores envolvendo a produção de sabão corroboraram com o processo de ensino-aprendizagem e com a possível conscientização dos estudantes, sobre os impactos ambientais provenientes do descarte inadequado de óleos advindos de frituras.

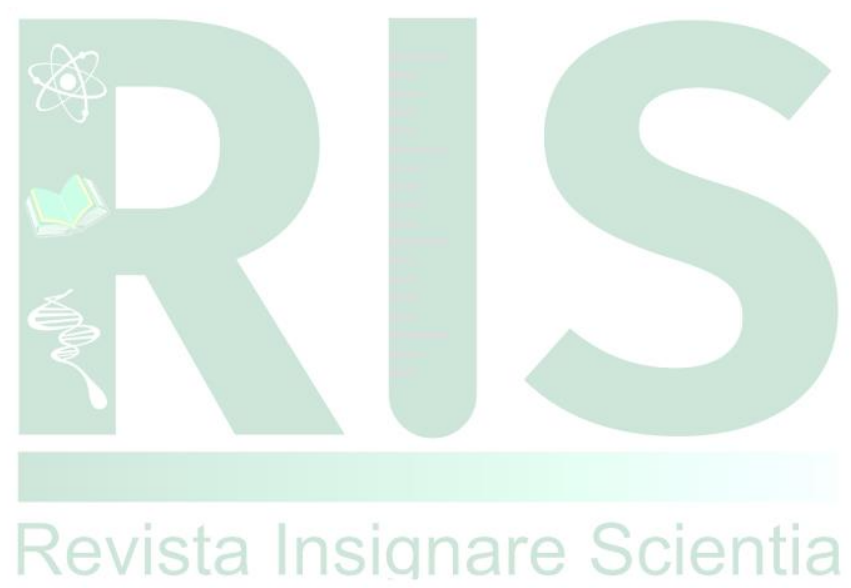




\section{REFERÊNCIAS}

ANVISA. Agência Nacional de Vigilância Sanitária , 2015. Disponível em:< http://portal.anvisa.gov.br/wps/portal/anvisa/home> Acesso em 15 de março de 2021.

ALBERICI, R. R.; PONTES, F. F. F. Reciclagem de óleo comestível usado através da fabricação de sabão. Revista Oficial do curso de Engenharia Ambiental - CREUPI. Espirito Santo do Pinhal, v.1, n.1, p. 73-76, dez 2004.

ALVES, E. S.; TOUTONGE, E.P.C. Os saberes das águas no ensino de ciências: intertrocas de conhecimentos e pessoas. Revista Insignare Scientia - RIS, v. 3, n. 4, p. 286-302, 20 nov. 2020.

BALDASSO, E.; PARADELA, A. L; HUSSAR, G. J. Reaproveitamento do óleo de fritura na fabricação de sabão. Revista Oficial de Engenharia Ambiental - CREUPI. São Paulo, v.7 n.1, março 2010. Disponível em Acesso em 11 fev 2021.

BARBOSA, A. B.; SILVA, R. R. Xampus. Revista Química Nova na Escola. São Paulo, n.2, p.3-6, nov. 1995.

BARDIN, L., Análise de conteúdo. São Paulo: Edições 70, 2011.

BORTOLUZZI, O. R. S. A poluição dos subsolos e águas pelos resíduos de óleo de cozinha. 2011. 36f. Monografia (Graduação em Ciência Biológica) - Departamento de Ciências Biológicas, Universidade Estadual de Goiás, Formosa, 2011.

BOTH, L. A Química Orgânica no Ensino Médio: na sala de aula e nos livros didáticos. 2007. Dissertação (Mestrado em Educação). Universidade Federal de Mato Grosso. 2007.

CASTRO, H. F. Sabões e detergentes Processos Químicos Industriais II UNIVERSIDADE DE SÃO PAULO Escola de Engenharia de Lorena - EEL 2009.

FERREIRA, M.; MÜNCHEN, S. A contextualização no ensino de ciências: reflexões a partir da Educação do Campo. Revista Insignare Scientia - RIS, v. 3, n. 4, p. 380-399, 20 nov. 2020.

FREIRE, P. Extensão ou comunicação? 14 ed. Rio de Janeiro: Paz e Terra, 2011.

FREIRE, P. Pedagogia da autonomia: saberes necessários à prática educativa. São Paulo: Paz e Terra, p 137-139. 2003.

FREIRE, P. Pedagogia da Esperança: Um reencontro com a Pedagogia do oprimido. $3^{a}$ ed. Rio de Janeiro: Paz e Terra, 1996. 
GATTI, B. A.; ANDRÉ, M. A relevância dos métodos de pesquisa qualitativa em educação no Brasil. In: WELLER, W.; PFAFF, N. (Orgs.). Metodologias da pesquisa qualitativa em Educação: teoria e prática. 2. ed. Petrópolis: Vozes, p. 29-38, 2011.

GIL, A. C. Métodos e técnicas de pesquisa social. São Paulo: Atlas, 2010.

GOODWIN, W. How do Structural Formulas Embody the Theory of Organic

Chemistry? The British Journal for the Philosophy of Science, Oxford, n. 61, p. 621633, 2010.

KATZ, J. J. Chemical and biological studies with deuterium. American scientist, 48, 4. p 544-580, 1960.

MARCONDES, M. E. R, SILVA, E. L.; TORRALBO, D., AKAHOSHI, L. H.; CARMO, M. P.; SUART, R. C.; MARTORANO, S. A.; SOUZA F. L. Oficinas temáticas no Ensino Público: formação continuada de professores. São Paulo: Imprensa Oficial do Estado de São Paulo, 2015.

MERCADANTE, R. Massa base para sabonetes. In Fabricando sabonetes sólidos. Projeto Gerart VII, [s.n], 2009. Disponível em: Acesso em: 11 setembro de 2013.

NETO, A. A.; LIMA, F. G. Fundamentos de Administração Financeira. São Paulo: ATLAS S.A, 376.p, 2010.

NETO, O. G. Z.; PINO, J. C. D. Trabalhando a química dos sabões e detergentes. Porto Alegre: Universidade Federal do Rio Grande do Sul, 2009.

NEVES, J. F. Produtos de Higiene e Limpeza e Controle de Processo. Imprensa Universitária-UFRRJ, Rio de Janeiro, 2003.

OLIVEIRA, A. M. C. A química no ensino médio e a contextualização: a fabricação dos sabões e detergentes como tema gerador de ensino aprendizagem. 2006. $120 \mathrm{f}$. Dissertação (Mestrado em Ensino de Ciências Naturais e Matemática) - Universidade Federal do Rio Grande do Norte, Natal, 2006.

OZAGO, O. G. N.; PINO, J. C. D. Trabalhando a química dos sabões e detergentes. Porto Alegre (RS):Fapergs, 72p, 2008.

PERUZZO, F. M.; CANTO, E. L. Química na Abordagem do Cotidiano. $4^{\mathrm{a}}$ edição. São Paulo: moderna, 205 P. 2010.

REIS, M. C. A história do sabão. Naturlink, 2009.

RIBEIRO, L. C. M.; SOUZA, A. C. S. BARRETO, R. A. S. S. BARBOSA J. M. Tipple AFV, Neves HCC, Suzuki K. Risco ocupacional pela exposição ao glutaraldeído em trabalhadores de serviços de endoscopia. Rev. Eletr. Enf. [Internet]. 2009. 
SANTOS, W. L. P. Contextualização no ensino de ciências por meio de temas CTS em uma perspectiva crítica. Ciência \& Ensino, vol. 1, número especial, novembro de 2007.

SILVA, D. O.; CARVALHO, A. O R. P. Soluções em Engenharia de Tratamento de Água. 2007.Disponível em:

http://www.kurita.com.br/adm/download/Tratamento_de_agua_de_Resfriamento.pdf>

VALENTIM, J. A. Extração de óleos essenciais por arraste a vapor: sequência didática para proporcionar aprendizagem de conceitos de Química. Dissertação (Mestrado em Ensino de Ciências Naturais). Universidade Federal do Mato Grosso, 2017.

VERANI, C. N.; GONÇALVES, D. R.; GONÇALVES, M.G. Sabões e detergentes como tema organizador de aprendizagens no ensino médio. Química Nova na Escola, N. 12, p. 16, 2000.

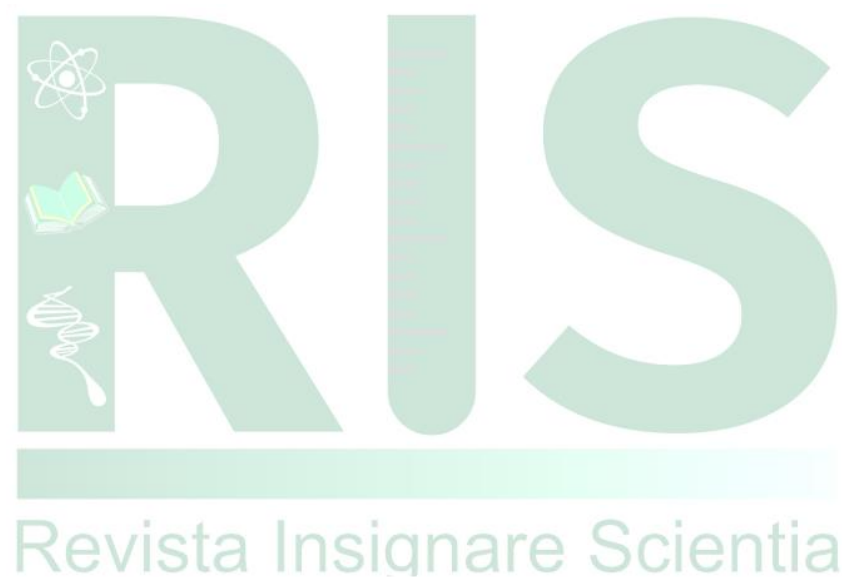

